\title{
Analysis of Correlation among Oral Environment, Oral Myofunction, and Oral Microorganisms
}

\author{
Seol-Hee $\mathrm{Kim}^{\dagger}$ \\ Department of Dental Hygiene, College of Medical Science, Konyang University, Daejeon 35365, Korea
}

\begin{abstract}
Background: Factors affecting oral function include tooth number, oral muscle strength, and oral diseases. This study aimed to investigate the relationship among oral environment, muscle, and microbiology.

Methods: Fifty-six elderly individuals in a day care center were included in the study. The survey regarding tongue and lip muscle strength and oral microorganisms was conducted from November to December 2018.

Results: Tongue and lip muscle strength were greater in men than women $(p>0.05)$. Tongue muscle strength was greater in the $\leq 80$-year-old group (34.94 \pm 9.85$)$ than the $\geq 90$-year-old group $(25.57 \pm 7.54)(p<0.05)$. Tongue muscle strength and lip muscle strength were greater in the $\geq 15$ functional teeth group ( $34.08 \pm 9.31$ and $9.25 \pm 1.63$, respectively) than in the $<15$ functional teeth group (28.08 \pm 7.53 and $7.76 \pm 1.51$, respectively) $(p<0.05)$. Age was significantly correlated with functional tooth number, denture use, and tongue muscle strength. The number of functional teeth was positively correlated with tongue muscle strength, lip muscle strength, and oral microorganisms. Denture use was negatively correlated with tongue and lip muscle strength. Tongue muscle strength was significantly correlated with lip muscle strength. The number of Eubacterium nodatum was higher in men than women. The number of Parvimonas micraand Enterococcus faecalis was higher in the groups with $\geq 15$ functional teeth, denture use, and greater tongue and lip muscle strength. The number of Lactobacillus caseiwas higher in the group that uses dentures and with greater tongue strength.

Conclusion: Oral microbiology is more important in oral environment and management than oral muscle function. The correlation between oral muscle and oral microorganism requires further study. Therefore, oral care training should be conducted to improve the oral care practice of elderly individuals, maintain oral health through oral care, and prevent the decrease in saliva secretion by aging.
\end{abstract}

Key Words: Lip, Microorganisms, Oral hygiene, Tongue, Tooth

\section{Introduction}

The mouth is responsible for mastication, deglutition, pronunciation, and aesthetic functions. The oral function is maintained through the interactions of the teeth, surrounding tissues, oral muscles, and saliva. A decline in oral function, such as tooth loss and decline in saliva secretion and oral muscle functions, is associated with aging ${ }^{1)}$. The main cause of tooth loss is tooth decay and periodontal diseases. Only $50.5 \%$ of individuals aged $\geq$ 65 years have $\geq 20$ natural teeth; those aged $\geq 70$ years have 15 teeth, and $48.8 \%$ experience discomfort with mastication $^{2)}$. Partial tooth loss and changes in the oral environment due to the use of multiple implants, prosthetics, or dentures in elderly individuals make oral care difficult.

In case of poor oral care, the formation of dental plaque, the cause of tooth decay and periodontal diseases, increases and the number of Actinobacillus actinomycetemcomitans, Porphyromonas gingivalis, Tannerella forsythensis, and Prevotella intermedia, which cause periodontal diseases, and Streptococcus mutans, which causes tooth decay, also increase $^{3)}$. Two of 3 adults in Korea develop periodontal diseases. Importantly, $12.4 \%$ of those aged between 20 and 39 years and almost $46.6 \%$ of those aged $\geq 60$ years develop the disease, thus requiring preventive care and 
early treatment of periodontal diseases in the elderly population. The problem that oral care is not appropriately performed in the elderly population compared to those in adults has been presented ${ }^{4)}$. The study results indicating a $2 \sim 7$ times greater risk of cardiovascular disease, diabetes, arthritis, and dementia in those with periodontal diseases ${ }^{5 \text {, }}$ suggest the importance of oral care in the elderly population to maintain overall health. Elderly individuals have a dry oral environment due to drug use and reduced saliva production ${ }^{6}$, and the risk of oral diseases, such as periodontal disease and tooth decay, increases in a dry oral environment ${ }^{7,8)}$. Because movements of the oral muscles, such as the tongue and lip muscles, stimulate the mouth to produce saliva ${ }^{9)}$, oral muscle exercises, such as gymnastics, and oral hygiene care training are necessary ${ }^{10,11)}$. However, research on the impact of oral myofunction activation and promotion of saliva production on the environmental changes in the oral microorganisms is insufficient.

The loss of physical muscles due to aging is related to the decrease in oral muscles. This decreases oral motion and affect oral functions such as mastication, deglutition, and pronunciation ${ }^{12}$. The main cause of the decrease in the ability to masticate is tooth loss. If tooth loss is not treated or dentures are used, there are limitations in the choice of food. Insufficient mastication makes it difficult to form a bolus suitable for deglutition, and soft food is selectively consumed, which hinders the activation of the mastication muscle $^{13)}$.

Among the oral muscles, tongue muscle strength plays an important role in mastication, deglutition, and pronunciation. The tongue moves the food in the mouth to a location that is good for mastication and pushes the food into the pharynx during deglutition. The decrease in tongue muscle strength can result in deglutition dysfunction, such as difficulty in swallowing food in one gulp and coughing while swallowing ${ }^{14)}$. Of the elderly population, $33.7 \%$ develop deglutition dysfunction due to the myotonia and delayed muscle spasm. This can lead to not only simple difficulty in consuming food but also complications such as inhalation pneumonia, malnutrition, and dehydration due to the difficulty in medication intake and entry of food in the airway, which lead to death ${ }^{15)}$.

The lip muscle closes to prevent food leakage through the palate when consuming food and helps in mastication by moving the food within the mouth along with the tongue and buccinator. It also serves the functions of blowing a whistle, blowing out a candle, and pronunciation. The decline in lip muscle strength leads to food leakage while eating and avoidance of eating with others, which decreases the quality of life ${ }^{14)}$.

Thus, oral myofunction plays an important role in mastication, deglutition, and pronunciation, and oral functions are maintained through the interaction of the teeth and saliva. The decline in oral myofunction can reduce saliva production during food consumption, decrease oral self-cleansing action due to muscle movements in the process of pronunciation or deglutition in adults, and affect the oral self-cleaning action to form an ideal environment for oral microorganisms. However, research on the correlations among the oral environment, oral myofunction, and oral microorganisms in the elderly population is inadequate. Therefore, this study aimed to analyze the correlation among oral environment, oral myofunction, and oral microorganisms and suggest the necessity of elderly oral care to maintain oral health and oral muscle training to maintain oral myofunction to provide basic data for the development of related programs.

\section{Materials and Methods}

\section{Research subjects}

After receiving the approval from the institutional review board of Konyang University (approval No. KYU-2018-138-01), this study was conducted on elderly individuals aged $\geq 65$ years in the Nonsan Day Care Center between November and December 2018. Research was conducted after explaining the purpose of the study on oral environment, oral myofunction, and oral microorganisms, describing the research ethics, and obtaining consent. Research subjects included both those with edentulous jaws and those with dentulous jaws. Participants who did not understand the description of the research process and those with severe temporomandibular disorders were excluded from this study. Study participants were provided with oral care product sets as gifts. The necessary sample size calculated with 
$\mathrm{G}^{*}$ Power version 3.1.9.2 at effect size of 0.15, significance level of 0.05 , power of 0.80 , and predictive variables 4 was 55. A total of 60 participants were evaluated, but a total of 56 were selected as the final sample after excluding 4 who did not complete the examination or had difficulties with the investigation.

\section{Research methods}

In the study, an oral microorganism examination was conducted, followed by oral environment and oral myofunction examinations.

In the oral environment examination, one dentist analyzed the number of remaining teeth, number of functional teeth, use of dentures, and need for treatment based on the national nutrition survey guidelines.

In the oral myofunction examination, the researcher measured tongue and lip muscle strength. The IOPI ${ }^{\mathrm{R}}$ (IOPI Medical, Redmond, WA, USA; Fig. 1) equipment was used for tongue muscle strength measurement, the tongue bulb was connected to the equipment, and the maximum pressure of the tongue with the palate was measured. For lip muscle strength measurement, the Lip de Cum $^{\circledR}$ (Cosmo-Instruments Co., Ltd., Tokyo, Japan; Fig. 1) equipment was used. Plastic lip holders connected to the sensor were placed on the upper and lower lips, and measurement was performed after the subject was asked to apply maximum pressure for 3 seconds in the vertical direction. For the results, each examination item was measured 3 times, and the average values were analyzed.



Fig. 1. Inspection machine.
In the oral microorganism examination, quantitative real-time polymerase chain reaction (PCR) was used to quantify the number of 16 types of bacteria, including Eikenella corrodens, Fusobacterium nucleatum, $P$. gingivalis, $P$. intermedia, and Treponema denticola. In DNA extraction, saliva sample was collected by gargling with $10 \mathrm{ml}$ of Easygen gargling liquid (YD science company, Seongnam, Korea) for 30 seconds, and DNA was extracted from the sample using QIAamp DNA Mini Kit (Qiagen, Hilden, Germany). Oligo Mix ${ }^{\circledR}$ (YD Life Science Company, Seongnam, Korea), which includes 3 types of oligonucleotide (forward primer, reverse primer, and probe) that specifically responds to each bacterium, was used. To prepare a PCR reaction sample, $9 \mu \mathrm{l}$ of Oligo $\mathrm{Mix}^{\circledR}, 10 \mu \mathrm{l}$ of $2 \times$ Probe qPCR Mix (Takara, Kusatsu, Japan), and $1 \mu$ l of template DNA were mixed. A 96-well plate with PCR reaction sample was placed in the CFX96 Touch $^{\text {TM }}$ Real-Time PCR Detection System (Bio-Rad, Hercules, CA, USA) to amplify the DNA. Then, initial denaturation for 3 minutes at $95^{\circ} \mathrm{C}$, denaturation for 5 seconds at $95^{\circ} \mathrm{C}$, annealing and extension for 30 seconds at $62^{\circ} \mathrm{C}$, and detection were repeated 40 times. For the quantification of the number of bacteria, cycle threshold value was identified using the CFX Manager software (Bio-Rad) and entered into the standard curve of each bacteria to extract the number of copies.

Table 1. Characterization of Sample

\begin{tabular}{lccc}
\hline \multicolumn{1}{c}{ Division } & $\begin{array}{c}\text { Men } \\
(\mathrm{n}=21)\end{array}$ & $\begin{array}{c}\text { Women } \\
(\mathrm{n}=35)\end{array}$ & $\begin{array}{c}\mathrm{t}(\mathrm{F}) / \\
\mathrm{p} \text {-value }\end{array}$ \\
\hline Age (y) & $82.71 \pm 8.25$ & $83.49 \pm 5.32$ & $-0.426 / 0.704$ \\
No. of functional teeth & $10.10 \pm 8.62$ & $10.60 \pm 9.83$ & $-0.194 / 0.842$ \\
Use of upper denture & & & $1.519 / 0.469$ \\
$\quad$ Full & $7(33.3)$ & $12(34.3)$ & \\
Partial & $9(42.9)$ & $10(28.6)$ & \\
$\quad$ None & $5(23.8)$ & $13(37.1)$ & \\
Use of lower denture & & & $0.423 / 0.809$ \\
$\quad$ Full & $4(19.0)$ & $9(25.7)$ & \\
Partial & $8(38.1)$ & $11(31.4)$ & \\
$\quad$ None & $9(42.9)$ & $15(42.9)$ & \\
Need of perio treatment & & & $0.051 / 0.534$ \\
$\quad$ Need & $15(71.4)$ & $24(68.6)$ & \\
Needlessness & $6(28.6)$ & $11(31.4)$ & \\
\hline
\end{tabular}

Values are presented as mean \pm standard deviation or $\mathrm{n}(\%)$. Data were analysed by t-test or ANOVA. 


\section{Analysis methods}

General characteristics of subjects and relative expression levels of the microorganisms were analyzed with descriptive statistics of mean and standard deviation. Oral myofunction due to oral environment and oral microorganisms due to oral environment and oral myofunction were analyzed using the t-test. The correlation of each factor was evaluated using Pearson's correlation analysis. The significance level of the statistical analysis was set to 0.05 .

The collected data were analyzed using PASW Statistics version 18.0 (IBM Corp., Armonk, NY, USA).

\section{Results}

\section{General characteristics of subjects}

There were 21 men $(37.5 \%)$ and 35 women $(62.5 \%)$ in the study. The average age was 83 years. The number of functional teeth by gender was 10.10 for men and 10.60 for women $(\mathrm{p}>0.05)$.

The use of dentures by gender showed that men used more partial dentures in the upper and lower jaw at $42.9 \%$ and $38.1 \%$, respectively, and women used more full denture in the upper jaw and partial dentures in the lower jaw at $34.3 \%$ and $31.4 \%$, respectively ( $p>0.05)$.

The need for periodontal treatment by gender was $71.4 \%$ in men and $69.6 \%$ in women $(p>0.05)$ (Table 1).

\section{Oral myofunction by general characteristics}

Tongue muscle strength was greater in men $(31.52 \pm$ 9.85) than in women $(29.66 \pm 8.02)$, and lip muscle strength was also greater in men $(8.49 \pm 1.41)$ than in women $(8.13 \pm 1.84)(\mathrm{p}>0.05)$.

Tongue muscle strength was greater in those aged $\leq 80$ years $(34.94 \pm 9.85)$ than those aged $\geq 90$ years $(25.57 \pm$ 7.54) $(\mathrm{p}<0.05)$. Tongue muscle strength was also greater in the group with $\geq 15$ functional teeth $(34.08 \pm 9.31)$ than that with $<15$ functional teeth $(28.08 \pm 7.53)$. Lip muscle strength was greater in the group with $\geq 15$ functional teeth $(9.25 \pm 1.63)$ than that with $<15$ functional teeth $(7.76 \pm 1.51)(\mathrm{p}<0.05)$.

Tongue muscle strength was greater in those who do not use upper jaw dentures $(34.90 \pm 9.12)$ than those who use full dentures $(26.90 \pm 7.18)$ and in those who do not use lower jaw dentures $(34.74 \pm 8.68)$ than those who use full

Table 2. Oral Myofunction according to Oral Environment

\begin{tabular}{|c|c|c|c|c|}
\hline Division & Tongue force & $\mathrm{t}(\mathrm{F}) / \mathrm{p}$-value & Lip force & $\mathrm{t}(\mathrm{F}) / \mathrm{p}$-value \\
\hline Gender & & $0.773 / 0.443$ & & $0.767 / 0.447$ \\
\hline Men $(n=21)$ & $31.52 \pm 9.85$ & & $8.49 \pm 1.41$ & \\
\hline Women $(n=35)$ & $29.66 \pm 8.02$ & & $8.13 \pm 1.84$ & \\
\hline Age (y) & & $3.663 / 0.032$ & & $1.128 / 0.331$ \\
\hline$\leq 80(\mathrm{n}=13)^{\mathrm{a}}$ & $34.94 \pm 9.85$ & & $8.84 \pm 1.78$ & \\
\hline $81 \sim 89(n=33)$ & $30.01 \pm 7.88$ & & $8.01 \pm 1.59$ & \\
\hline$\geq 90(\mathrm{n}=10)$ & $25.57 \pm 7.54$ & & $8.36 \pm 1.89$ & \\
\hline No. of functional teeth & & $-2.915 / 0.005$ & & $-3.388 / 0.001$ \\
\hline$<15(\mathrm{n}=37)$ & $28.08 \pm 7.53$ & & $7.76 \pm 1.51$ & \\
\hline$\geq 15(\mathrm{n}=19)$ & $34.08 \pm 9.31$ & & $9.25 \pm 1.63$ & \\
\hline Use of upper denture & & $4.557 / 0.015$ & & $3.520 / 0.037$ \\
\hline None $(\mathrm{n}=19)^{\mathrm{b}}$ & $34.90 \pm 9.12$ & & $9.02 \pm 1.33$ & \\
\hline Partial $(n=19)$ & $29.51 \pm 8.21$ & & $8.22 \pm 2.02$ & \\
\hline Full $(n=18)$ & $26.90 \pm 7.18$ & & $7.60 \pm 1.39$ & \\
\hline Use of lower denture & & $6.515 / 0.003$ & & $2.735 / 0.074$ \\
\hline None $(n=24)^{a}$ & $34.74 \pm 8.68$ & & $8.85 \pm 1.66$ & \\
\hline Partial $(n=19)$ & $26.49 \pm 8.38$ & & $7.89 \pm 1.74$ & \\
\hline Full $(n=13)$ & $27.92 \pm 5.39$ & & $7.72 \pm 1.42$ & \\
\hline
\end{tabular}

Values are presented as mean \pm standard deviation.

Data were analysed by t-test or ANOVA.

${ }^{a, b}$ The same characters are not significant by Scheffe multiple comparison $(\mathrm{p}<0.001, \mathrm{p}<0.05)$. 


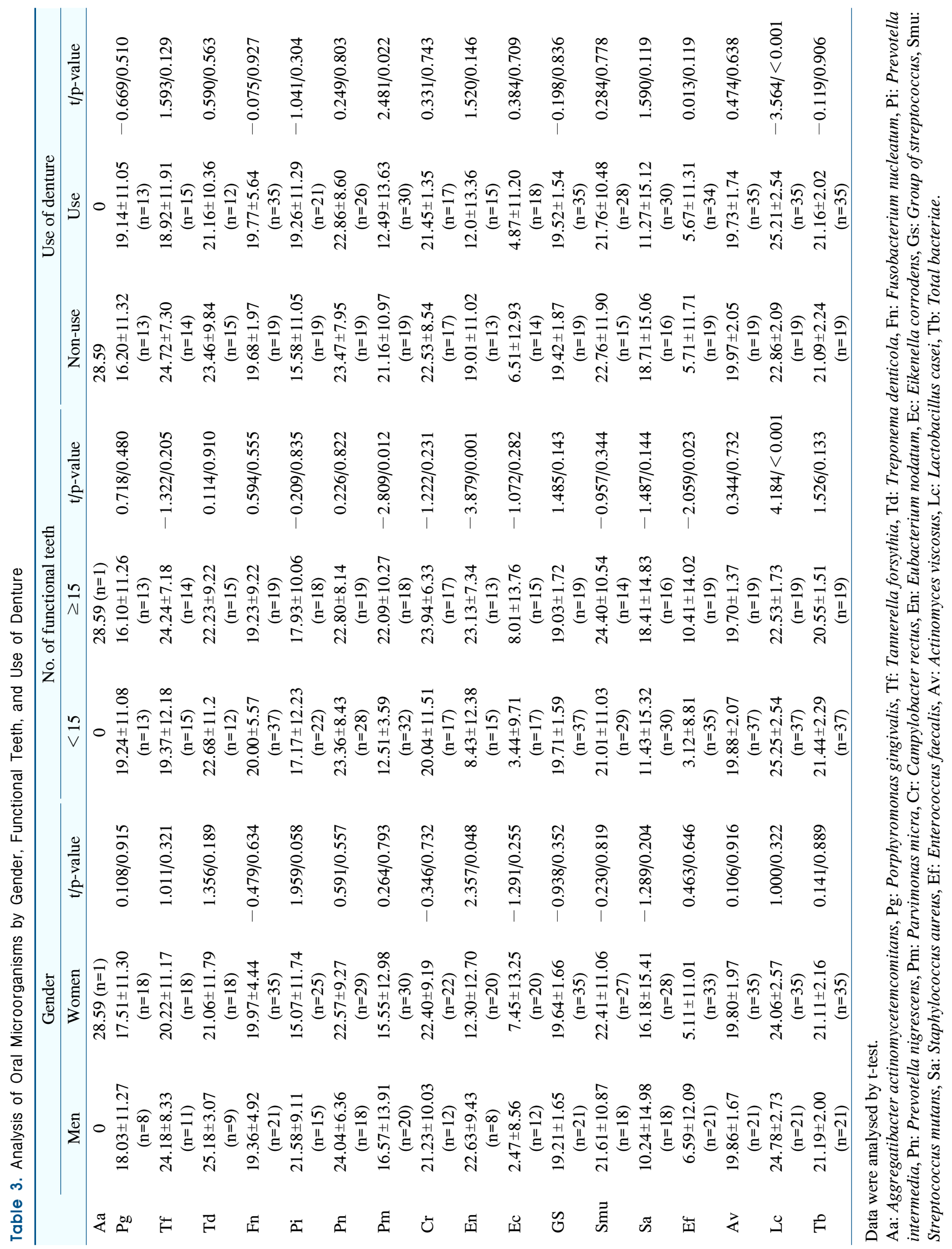




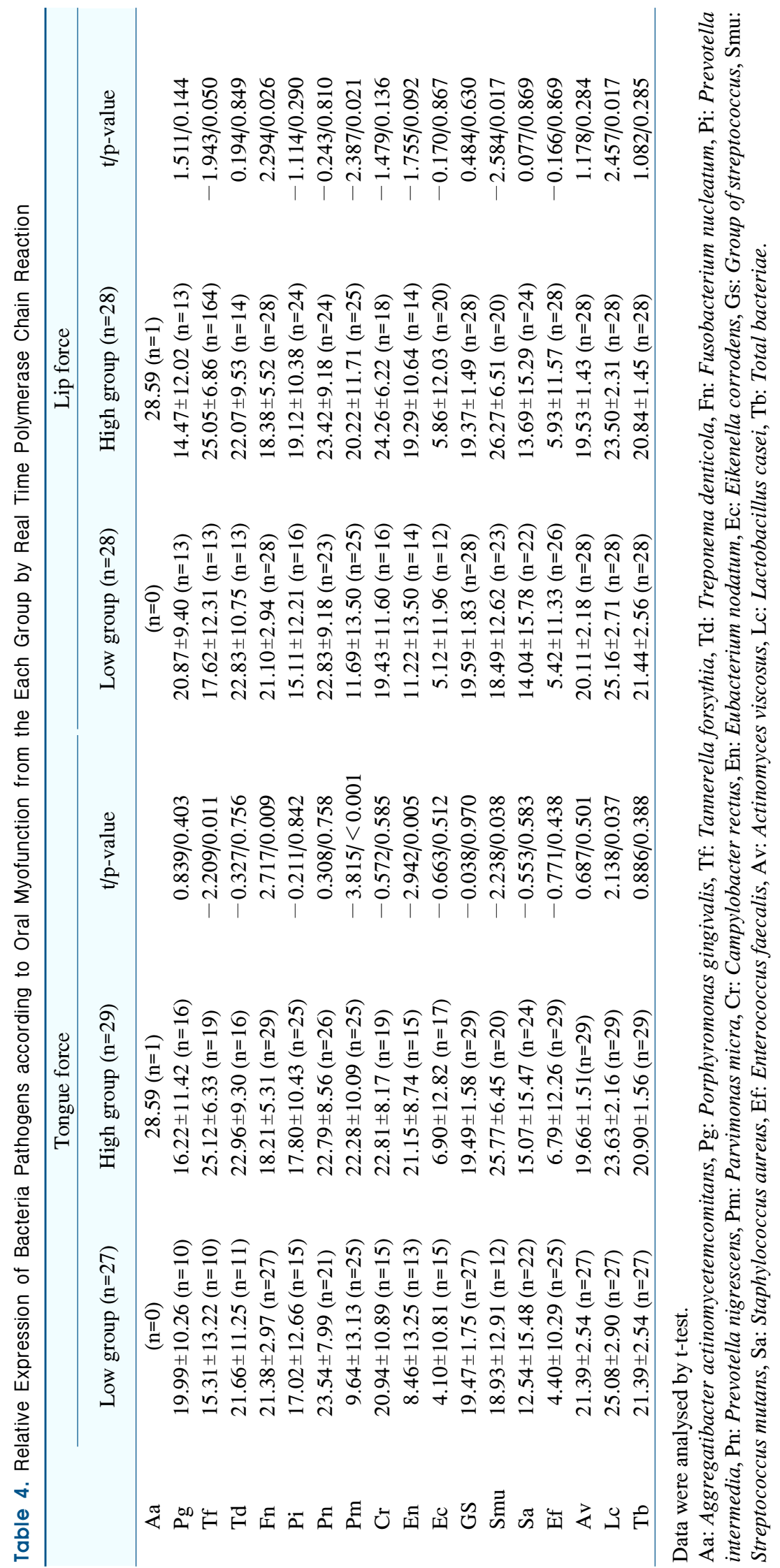


denture $(27.92 \pm 5.39)(\mathrm{p}<0.05)$ (Table 2).

3. Oral microorganism analysis by gender, number of functional teeth, and denture use

The number of Eubacterium nodatum was higher in men $(22.63 \pm 9.43)$ than women $(12.30 \pm 12.70)(\mathrm{p}<0.05)$. The number of Parvimonas micra was higher in the group with $\geq 15$ functional teeth $(22.09 \pm 10.27)$ compared to that with $<15$ functional teeth $(12.51 \pm 3.59)$, while that of $E$. nodatum was higher in the group with $\geq 15$ functional teeth (23.13 \pm 7.34$)$ compared to that with $<15$ functional teeth $(8.43 \pm 12.38)(\mathrm{p}<0.05)$. The number of Enterococcus faecalis was higher in the group with $\geq 15$ functional teeth $(10.41 \pm 14.02)$ compared to that with $<15$ functional teeth $(3.12 \pm 8.81)(\mathrm{p}<0.05)$.

The number of $P$. micra was higher in the group that does not use dentures $(21.16 \pm 10.97)$ compared to the group that does (12.49 \pm 13.63 ), while that of Lactobacillus case $i$ was higher in the group that uses dentures $(25.21 \pm$ $2.54)$ compared to the group that does not $(22.86 \pm 2.09)(\mathrm{p}<$ 0.05) (Table 3).

4. Oral microorganism expression by oral myofunction

The number of $F$. nucleatum was lower in the group with upper strength $(18.21 \pm 5.31)$ than the group with lower strength (21.38 \pm 2.97$)$. Moreover, the number of Lactobacillus casei was lower in the group with upper strength (23.63 \pm 2.16$)$ than the group with lower strength $(25.08 \pm 2.90)(\mathrm{p}<0.05)$. The number of $P$. micra was higher in the group with upper strength $(22.28 \pm 10.09)$ than the group with lower strength $(9.64 \pm 13.13)$. The number of $E$. nodatum was higher in the group with upper strength $(21.15 \pm 8.74)$ than the group with lower strength (8.46 \pm 13.25$)$, and that of $S$. mutans was also higher in the group with upper strength $(25.77 \pm 6.45)$ than the group with lower strength $(18.93 \pm 12.91)(\mathrm{p}<0.05)$.

The number of $F$. nucleatum was lower in the group with upper strength $(18.38 \pm 5.52)$ than the group with lower strength (21.10 \pm 2.94$)$, and that of $L$. case $i$ was also lower in the group with upper strength $(23.50 \pm 2.31)$ than the group with lower strength $(25.16 \pm 2.71)(\mathrm{p}<0.05)$. The number of $P$. micra was higher in the group with upper strength $(20.22 \pm 11.71)$ than the group with lower strength $(11.69 \pm 13.50)$, and that of $S$. mutans was also higher in the group with upper strength $(26.27 \pm 6.51)$ than the group with lower strength $(18.49 \pm 12.62)(\mathrm{p}<0.05)$ (Table 4).

\section{Correlation between oral environment and oral myofunction and oral microorganisms}

Age had significant correlations with the number of functional teeth $(\mathrm{r}=-0.300, \mathrm{p}<0.05)$, use of dentures $(\mathrm{r}=0.282, \mathrm{p}<0.05)$, and tongue muscle strength $(\mathrm{r}=-0.350$, $\mathrm{p}<0.001)$. The number of functional teeth had significant correlations with use of dentures $(r=-0.568, p<0.001)$, tongue muscle strength $(\mathrm{r}=0.496, \mathrm{p}<0.001)$, lip muscle strength $(\mathrm{r}=0.474, \mathrm{p}<0.001)$, and oral microorganisms $(\mathrm{r}=0.496, \mathrm{p}<0.001)$. The use of dentures had a significant correlation with tongue muscle strength $(\mathrm{r}=-0.412, \mathrm{p}<$ 0.001 ). Tongue muscle strength had a significant positive correlation with lip muscle strength $(\mathrm{r}=0.527, \mathrm{p}<0.001)$ (Table 5).

Table 5. Correlations of Oral State, Oral Myofunction, and Microorganisms

\begin{tabular}{|c|c|c|c|c|c|c|}
\hline Variable & Age & $\begin{array}{c}\text { No. of } \\
\text { functional teeth }\end{array}$ & Use of denture & Tongue force & Lip force & Total bacteriae \\
\hline Age & 1 & & & & & \\
\hline No. of functional teeth & $-0.300 *$ & 1 & & & & \\
\hline Use of denture & $0.282^{*}$ & $-0.568 * *$ & 1 & & & \\
\hline Tongue force & $-0.350 * *$ & $0.496^{* *}$ & $-0.412 * *$ & 1 & & \\
\hline Lip force & -0.083 & $0.474 * *$ & -0.233 & $0.527 * *$ & 1 & \\
\hline Total bacteriae & 0.048 & $-0.286^{*}$ & -0.061 & -0.169 & 0.178 & 1 \\
\hline
\end{tabular}

Data were analysed by Pearson's correlation analysis.

${ }^{*} \mathrm{p}<0.05,{ }^{*} \mathrm{p}<0.001$. 


\section{Discussion}

This study aimed to analyze the correlation among oral environment, oral myofunction, and oral microorganisms and present the necessity for oral muscle training to maintain oral myofunction and elderly care to maintain oral health.

The average age of the research subjects was 83 years, and the average number of functional teeth was 10.3. Although age and the number of remaining teeth affect mastication, the study conducted by Ikebe et al. ${ }^{1)}$ suggests that age is not related to mastication. This is because mastication ability can be maintained if the number of remaining teeth is high even with an increase in age. If tooth loss is not considered a property of biological aging, this signifies that aging itself is not a risk factor for mastication dysfunction. The need for periodontal treatment by gender is about $70 \%$; with increasing age, tooth loss and periodontal disease reduce the mastication ability, decrease the oral sensation relayed to the central nervous system, and limit the choice of food. Because mastication not only helps with food consumption but also promotes and maintains the physical health including cognitive function, tooth maintenance and oral-related diet in elderly individuals through continuous oral care from adulthood are necessary ${ }^{16)}$. Mastication function maintains cognitive functions, and this is because mastication increases the activation of frontal cortex and hippocampus, which increases cognition. Because epidemiological research suggests that the decrease in the number of remaining teeth and reduction in denture use can decrease the mastication ability and are directly related to the onset of dementia ${ }^{17)}$, the need for tooth maintenance and prevention of periodontal diseases was emphasized for not only oral health but also maintenance of mental health.

In this study, although men had higher oral myofunction (tongue and lip muscle strengths) than women, there was no statistically significant difference and muscle strength significantly decreased with increasing age. Although some studies suggest that the mastication ability of elderly individuals who use dentures has large differences by gender and that the mastication power and efficiency of men is drastically higher, the fact that the tongue muscle strength of women are not greatly decreased suggests that women supplement the insufficient mastication power using the tongue muscles to maintain the mastication power that is lower in women than in $\operatorname{men}^{17,18)}$.

It was found that the group with $\geq 15$ functional teeth had greater oral muscle strength than the group with $<15$ functional teeth, and the tongue muscle strength of the group who do not use dentures was greater. Full denture users had slightly greater tongue and lip muscle strengths compared to partial denture users. In the case of full denture, oral muscle strength is thought to be activated to increase the maintenance power in the mouth and additionally requires related research. Koshino et al. ${ }^{19)}$ reported that aging reduces myofunction to decrease sensation and mobile functions. Individual myofunction declines appear differently; the changes in the oral myofunction can be accelerated with increase in age and tooth loss. If at least 20 teeth are maintained, oral muscle strength decline in those with edentulous jaws is said to be small, and changes do not appear regardless of age. Hara et al. ${ }^{13)}$ also suggested that age relates to tongue muscle strength, more verbal activities before the start of aging can prevent the decline in tongue muscle strength from increasing age, and maintaining oral myofunction through oral muscle training is important.

By gender, the number of $E$. nodatum, which is observed in periodontitis and peri-implantitis, was higher in men. This was believed to be related to the fact that the oral care practice rate was higher in women than men. This study was conducted on elderly individuals in the nursing home day care center, and the study on oral care practice rate found that one care practice per day was normal. A method to increase the oral care practice rate in elderly individuals with less activities of daily living is necessary. Some studies suggest that sodium bicarbonate gargle reduces the burden of buying chlorhexidine gargle and can be an inexpensive and effective alternative to mouthwash in the case of the elderly individual with poor oral care. Through related studies, a new approach to manage oral microorganisms easily without economic difficulties for the elderly population was required ${ }^{8,20)}$.

The number of $P$. micra and $E$. faecalis, which are cause of periodontitis, was higher in the group with $\geq 15$ 
functional teeth, those who do not use dentures, and those with upper-level tongue and lip muscle strengths. This is because periodontal diseases develop in the remaining teeth. The number of $L$. casei, which increases with decay progression, was higher in the group who uses dentures and those with lower-level tongue muscle strength. In the case of denture users, partial denture users were found to have higher expressions of oral microorganisms compared to full denture users. In the case of partial denture users, the risk of decay was higher due to the challenge of managing residual teeth and poor denture care. The number of $E$. nodatum, the cause of periodontitis, and $S$. mutans, the cause of tooth decay, was found to be higher in the group with upper-level tongue muscle strength. According to the correlation analysis results of this study, the number of teeth and tongue muscle strength showed a positive correlation. It is believed that more remaining teeth are associated with higher tongue muscle strength, thereby affecting oral microorganisms. For the expression of oral microorganisms by oral myofunction, the decrease in oral microorganisms from self-cleaning actions was considered if tongue and lip muscle strengths were high. However, to confirm this, it is suggested that microorganism examinations are needed by part.

Symptoms related to poor oral care, low salivary $\mathrm{pH}$, and salivary changes can increase the risk of periodontal disease, tooth decay, and fungal infections such as candidiasis because the natural balance of the microorganisms is sometimes hindered ${ }^{6}$. Policy support was required to educate older adults with lower immunity to recognize that oral microorganisms are a risk factor for systemic diseases and perform correct oral care and elderly individuals to perform continuous oral care at dental institutions without economic burden.

Age was significantly correlated with the number of functional teeth, denture use, and tongue muscle strength. The number of functional teeth had a significant positive correlation with tongue and lip muscle strengths and oral microorganisms. Denture use had significant negative correlations with tongue and lip muscle strengths. Finally, tongue muscle strength had a significant positive correlation with lip muscle strength. In the study on tooth loss, tongue pressure, and mastication power of adults and elderly individuals by Hara et al. ${ }^{13)}$, there was a significant correlation between tongue muscle strength and age. A study by Kim et al. ${ }^{21)}$ found that the number of remaining teeth was related to gender, education level, oral function of chewing and talking, and oral health. Sakai et al. ${ }^{22)}$ stated that lip muscle strength is related to hand grip, lip drooping is related to aging, and decline in lip muscle strength is related to muscle reduction and deglutition difficulty. The decline in mastication, deglutition, and pronunciation functions due to the decline in oral myofunction ultimately has a negative impact on the quality of life of the elderly population ${ }^{23)}$. Although efforts to improve the oral environment that changed due to aging and pronunciation through oral muscle strength training are necessary, medical institutions that provide education regarding these are extremely $\operatorname{rare}^{24)}$. Measures were required to universalize education through oral muscle training programs so that oral muscles could function with accurate patterns. Moreover, preventive measures are needed to maintain oral function of the elderly population. In their study, Lee et al. ${ }^{25)}$ suggested that efforts should be made to establish an oral exercise as a part of the community elderly exercise program. A study by Jang and Hwang ${ }^{26)}$ revealed that the elderly population are a group that actively participate and can obtain great health benefits because they have higher interest in health compared to other age groups and that the provision of effective oral health care service is necessary.

These research results were obtained from some elderly individuals, and there are limitations in generalization. It is possible that the sample was biased in the high-risk group with relatively poor oral care because the subjects were elderly individuals in the day care centers. Thus, a comparative study with many groups is necessary. However, this study is significant in that it focused on oral microorganisms by oral environment and oral myofunction, which has not been previously studied, and suggested the importance of oral myofunction, which affects not only mastication but also deglutition and pronunciation, among oral functions.

It is necessary to perform continuous oral care and recognize the importance of oral care from youth and adulthood before the decline in oral health and oral 
myofunction. Given that the decline in oral myofunction due to tooth loss and aging has been suggested, recognizing the importance of oral myofunction and performing muscle training will help increase the quality of life related to oral health, such as mastication, deglutition, pronunciation, and aesthetics, in the elderly population.

\section{Notes}

\section{Conflict of interest}

No potential conflict of interest relevant to this article was reported.

\section{Ethical approval}

This study was approved by the Institutional Review Board of Konyang University (approval No. KYU-2018138-01).

\section{ORCID}

Seol-Hee Kim, https://orcid.org/0000-0003-1996-1306

\section{Acknowledgements}

This work was supported by the National Research Foundation of Korea (NRF) grant funded by the Korea government (MSIT) (No. NRF-2017R1C1B5017668).

\section{References}

1. Ikebe $\mathrm{K}$, Matsuda $\mathrm{K}$, Kagawa $\mathrm{R}$, et al.: Association of masticatory performance with age, gender, number of teeth, occlusal force and salivary flow in Japanese older adults: is ageing a risk factor for masticatory dysfunction? Arch Oral Biol 56: 991-996, 2011.

https://doi.org/10.1016/j.archoralbio.2011.03.019

2. Ministry of Health and Welfare, Korea Centers for Disease Control and Preventive: 2014 Korea Health Statistics I--Korea National Health and Nutritional Examination Survey (KNHANES) VI-2 (2014). Ministry of Health and Welfare, Sejong, pp.214-220, 2014.

3. Boutaga K, van Winkelhoff AJ, Vandenbroucke-Grauls CM, Savelkoul PH: Periodontal pathogens: a quantitative comparison of anaerobic culture and real-time PCR. FEMS Immunol Med Microbiol 45: 191-199, 2005. https://doi.org/10.1016/j.femsim.2005.03.011

4. Kim SH: Effects of nutrient intake on oral health and chewing difficulty by age group. J Korea Acad-Ind Cooper Soc 19: 202-209, 2018. https://doi.org/10.5762/KAIS.2018.19.2.202

5. Sato S, Ito IY, Lara EH, Panzeri H, Albuquerque Junior RF, Pedrazzi V: Bacterial survival rate on toothbrushes and their decontamination with antimicrobial solutions. J Appl Oral Sci 12: 99-103, 2004 https://doi.org/10.1590/S1678-77572004000200003

6. N'gom PI, Woda A: Influence of impaired mastication on nutrition. J Prosthet Dent 87: 667-673, 2002. https://doi.org/10.1067/mpr.2002.123229

7. Lynge Pedersen AM, Belstrøm D: The role of natural salivary defences in maintaining a healthy oral microbiota. J Dent 80 Suppl 1: S3-S12, 2019. https://doi.org/10.1016/j.jdent.2018.08.010

8. Alves C, Menezes R, Brandão M: Salivary flow and dental caries in Brazilian youth with type 1 diabetes mellitus. Indian J Dent Res 23: 758-762, 2012. https://doi.org/10.4103/0970-9290.111254

9. Pedersen A, Sørensen CE, Proctor GB, Carpenter GH: Salivary functions in mastication, taste and textural perception, swallowing and initial digestion. Oral Dis 24: 1399-1416, 2018. https://doi.org/10.1111/odi.12867

10. Jo ED, Kim ES, Hong HK, Han GS. Factors analysis of the oral health-related quality of life in the elderly. J Korean Soc Dent Hyg 19: 55-64, 2019. https://doi.org/10.13065/jksdh.20190004

11. Jang YE, Heo SS, Kim EK, Kim NH. A study on the needs of independent dental hygiene practices in the public dental hygienists. J Korean Soc Dent Hyg 17: 505-513, 2017. https://doi.org/10.13065/jksdh.2017.17.03.505

12. Laguna L, Sarkar A, Artigas G, Chen J: A quantitative assessment of the eating capability in the elderly individuals. Physiol Behav 147: 274-281, 2015. https://doi.org/10.1016/j.physbeh.2015.04.052

13. Hara K, Tohara H, Kenichiro K, et al.: Association between tongue muscle strength and masticatory muscle strength. $\mathrm{J}$ Oral Rehabil 46: 134-139, 2019. https://doi.org/10.1111/joor.12737

14. Holland G, Jayasekeran V, Pendleton N, Horan M, Jones M, Hamdy S: Prevalence and symptom profiling of oropharyngeal dysphagia in a community dwelling of an elderly population: 
a self-reporting questionnaire survey. Dis Esophagus 24: 476480, 2011. https://doi.org/10.1111/j.1442-2050.2011.01182.x

15. Ertekin C, Aydogdu I: Neurophysiology of swallowing. Clin Neurophysiol 14: 2226-2244, 2003.

https://doi.org/10.1016/j.neuroimage.2008.10.012

16. Ono Y, Yamamoto T, Kubo KY, Onozuka M: Occlusion and brain function: mastication as a prevention of cognitive dysfunction. J Oral Rehabil 37: 624-640, 2010.

https://doi.org/10.1111/j.1365-2842.2010.02079.x

17. Kawahata M, Ono Y, Ohno A, Kawamoto S, Kimoto K, Onozuka M: Loss of molars early in life develops behavioral lateralization and impairs hippocampus-dependent recognition memory. BMC Neurosci 15: 4, 2014.

https://doi.org/10.1186/1471-2202-15-4

18. Shiga H, Kobayashi Y, Katsuyama H, Yokoyama M, Arakawa I: Gender difference in masticatory performance in dentate adults. J Prosthodont Res 56: 166-169, 2012. https://doi.org/10.1016/j.jpor.2012.02.001

19. Koshino H, Hirai T, Ishijima T, Ikeda Y: Tongue motor skills and masticatory performance in adult dentates, elderly dentates, and complete denture wearers. J Prosthet Dent 77: 147-152, 1997. https://doi.org/10.1016/S0022-3913(97)70228-2

20. Chandel S, Khan MA, Singh N, Agrawal A, Khare V: The effect of sodium bicarbonate oral rinse on salivary $\mathrm{pH}$ and oral microflora: a prospective cohort study. Natl J Maxillofac
Surg 8: 106-109, 2017.

https://doi.org/10.4103/njms.NJMS_36_17

21. Kim HN, Kim KR, Kim JB: The association between number of present teeth and oral function in Korean adults aged 55 84 years. J Dent Hyg Sci 15: 340-347, 2015. https://doi.org/10.17135/jdhs.2015.15.3.340

22. Sakai K, Nakayama E, Tohara H, et al.: Diagnostic accuracy of lip force and tongue strength for sarcopenic dysphagia in older inpatients: a cross-sectional observational study. Clin Nutr 38: 303-309, 2019.

https://doi.org/10.1016/j.clnu.2018.01.016

23. Kim SH, Lim SA, Park SJ, Kim DK: Assessment oral health-related quality of life using the Oral Health Impact Profile(OHIP). J Korean Acad Oral Health 28: 555-569, 2004.

24. Burr JA, Lee HJ: Social relationships and dental care service utilization among older adults. J Aging Health 25: 191-120, 2013. https://doi.org/10.1177/0898264312464497

25. Lee SM, Cho EP, Hwang YS, Kang BW: The change of oral function before and after practicing program for oral function improving. J Dent Hyg Sci 11: 497-503, 2011.

26. Jang KA, Hwang IC: Effects of mouth excercise on the improvements of oral function in elderly men. J Dent Hyg Sci 11: 257-263, 2011. 